\title{
Profiling of cell stress protein expression in cardiac tissue of cardiosurgical patients undergoing remote ischemic preconditioning: implications for thioredoxin in cardioprotection
}

Karina Zitta ${ }^{1 \dagger}$, Patrick Meybohm ${ }^{1,2+}$, Matthias Gruenewald ${ }^{1}$, Jochen Cremer $^{3}$, Kai D Zacharowski ${ }^{2}$, Jens Scholz ${ }^{1}$, Markus Steinfath ${ }^{1}$ and Martin Albrecht ${ }^{*}$

\begin{abstract}
Background: Transient episodes of ischemia in a remote organ (remote ischemic preconditioning, RIPC) can attenuate myocardial ischemia/reperfusion injury but the underlying mechanisms of RIPC in the target organ are still poorly understood. Recent animal studies suggested that the small redox protein thioredoxin may be a potential candidate for preconditioning-induced organprotection. Here we employed a human proteome profiler array to investigate the RIPC regulated expression of cell stress proteins and particularly of thioredoxin in heart tissue of cardiosurgical patients with cardiopulmonary bypass (CPB).

Methods: RIPC was induced by four 5 minute cycles of transient upper limb ischemia/reperfusion using a blood pressure cuff. Right atrial tissue was obtained from patients receiving RIPC $(N=19)$ and control patients $(N=19)$ before and after CPB. Cell stress proteome profiler arrays as well as Westernblotting and ELISA experiments for thioredoxin (Thio-1) were performed employing the respective tissue samples.

Results: Protein arrays revealed an up-regulation of 26.9\% (7/26; CA IX, Cyt C, HSP-60, HSP-70, pJNK, SOD2, Thio-1) of cell stress associated proteins in RIPC tissue obtained before CPB, while 3.8\% (1/26; SIRT2) of the proteins were down-regulated. Array results for thioredoxin were verified by semi-quantitative Westernblotting studies which showed a significant up-regulation of thioredoxin protein levels in cardiac tissue samples of RIPC patients taken before CPB (RIPC: $5.36 \pm 0.85$ a.u.; control: $3.23 \pm 0.39$ a.u.; $P<0.05$ ). Quantification of thioredoxin levels in tissue of RIPC and control patients by ELISA experiments further confirmed the Westernblotting results (RIPC: $0.30 \pm 0.02 \mathrm{ng} / \mathrm{mg}$ protein; control: $0.24 \pm 0.02 \mathrm{ng} / \mathrm{mg}$ protein; $\mathrm{P}<0.05)$.

Conclusion: We provide evidence for thioredoxin as a RIPC-induced factor in heart tissue of cardiosurgical patients and identified several cell stress associated proteins that are regulated by RIPC and may play a role in RIPC-mediated cardioprotection.
\end{abstract}

Keywords: Remote ischemic preconditioning, Cardioprotection, Cardiac surgery, Protein expression, Thioredoxin

\footnotetext{
*Correspondence: martin.albrecht@uksh.de

†Equal contributors

'Department of Anaesthesiology and Intensive Care Medicine, University

Hospital Schleswig-Holstein, Schwanenweg 21, 24105 Kiel, Germany

Full list of author information is available at the end of the article
} 


\section{Background}

Ischemia/reperfusion injury is commonly found during cardiac surgery and can lead to myocardial and neurological dysfunction as well as increased mortality [1-3].

In the last decades it has been shown that transient episodes of ischemia (ischemic preconditioning) if applied before prolonged ischemia/reperfusion injury have the potential to reduce myocardial infarction [4-9]. Subsequent trials revealed that ischemic preconditioning does not only act locally, but is also able to protect remote tissues from ischemia/reperfusion injury, a phenomenon described as remote ischemic preconditioning (RIPC). RIPC can be induced by inflation and deflation of a blood pressure cuff located at the upper or lower limb. This procedure has been shown to attenuate myocardial injury in a number of clinical situations, especially during cardiac surgery [6,10-16].

RIPC-mediated signalling events within the myocardial tissue possibly involve protein kinase $\mathrm{C}$ activation, phosphorylation of pro-survival kinases akt and erk1/2 [17-22] and phosphorylation of STAT5 [23]. Despite the advances in the clinical application of RIPC and increasing knowledge concerning the RIPC-released humoral factors and induced signalling events, there is still an apparent lack of information regarding the proteins that are regulated by RIPC within the myocardial tissue $[24,25]$. We have recently shown that the activities of matrix metalloproteinases 2 and 9 (MMP-2/9) as well as the expression levels of procaspase- 3 and enzymatic activities of myeloperoxidase are increased in heart tissue of cardiosurgical patients receiving RIPC [26,27]. However, the precise cellular mechanisms that are responsible for the RIPC-mediated cardioprotection are still unclear and discussed controversially.

The thioredoxin system is one of the central antioxidant systems in mammalian cells, maintaining a reducing environment by catalyzing electron flux from nicotinamide adenine dinucleotide phosphate through thioredoxin reductase to thioredoxin, which reduces its target proteins using highly conserved thiol groups [28-31]. Interestingly, several authors have suggested that thioredoxin could also be involved in preconditioning induced cardioprotection [32-34].

Here we performed proteomic profiling with cardiac tissue obtained from cardiosurgical patients subjected to RIPC or sham intervention and investigated the expression levels of 26 cell stress associated proteins. We moreover focused on the potential role of thioredoxin by verifying the results of the proteome profiling approach using Westernblotting and ELISA experiments.

\section{Methods}

\section{Experimental protocol}

The study protocol, patient information, and informed consent were approved by the Ethics Committee of the
University Hospital Schleswig-Holstein, Campus Kiel, Germany (Reference number: A165/08). The study was performed in accordance with the fourth revision of the Declaration of Helsinki (1996) and is registered at Clinical Trials.gov (NCT00877305). Employing patient sera and biopsy material, two experimental sub-studies have been published recently ([26,27]; Additional file 1: Table S1).

Aim of the study was to identify cell stress associated proteins in cardiac tissue samples of cardiosurgical patients with and without RIPC and patients included into the study were selected based on the criteria described earlier [26]. Each patient (age $\geq 18$ years) gave written informed consent to participate in the study. All types of cardiac surgery in which cardiopulmonary bypass (CPB) was used were included. Patients were randomized to group RIPC or control in a double-blinded fashion. RIPC was induced by four cycles of upper limb ischemia (5-minutes blood-pressure cuff inflation to $200 \mathrm{mmHg}$ and 5-minutes cuff deflation) after induction of total intravenous anaesthesia (propofol and sufentanil). In patients assigned to the control group we used four cycles of 5-minutes bloodpressure cuff inflation to $20 \mathrm{mmHg}$ and 5-minutes cuff deflation without any limb ischemia (Figure 1).

Demographic data, information regarding the comorbidities, medications and ICU (intensive care unit) data of the patients employed in the clinical trial and experimental sub-studies (NCT00877305) have been presented recently [26,27]. Cardiac tissue of the right atrium was collected from RIPC and control patients before as well as after CPB. Serum concentrations of cardiac troponin $\mathrm{T}$ $(\mathrm{c} \operatorname{Tn} \mathrm{T})$ were employed as a marker for myocardial damage $[35,36]$ and in all experiments patients in the RIPC group displayed significantly lower $(\mathrm{P}<0.001)$ levels of $\mathrm{cTnT}$ compared to control patients (data not shown).

\section{Cell stress proteome profiler arrays}

Proteome profiling was performed using commercially available cell stress proteome profiler arrays (R\&D Systems, Minneapolis, USA; \#ARY018) and the manufacturer's protocol provided with the assay kit. Expression levels of 26 cell stress associated proteins were evaluated in cardiac tissue that was derived from cardiosurgical patients (control and RIPC) before as well as after CPB. Equal amounts of protein $(15 \mu \mathrm{g})$ of each biopsy sample were pooled and applied to the respective array membrane. Densitometric analyses of the arrays were performed using the ImageJ 1.41 o software (ImageJ, NIH, USA). Only proteins with signal intensities $\geq 10 \%$ of the internal reference control protein spot were further analysed.

\section{Westernblotting}

Based on the results of the cell stress proteome profiler arrays, thioredoxin was chosen as a promising candidate for RIPC-mediated cardioprotection [32-34] and 


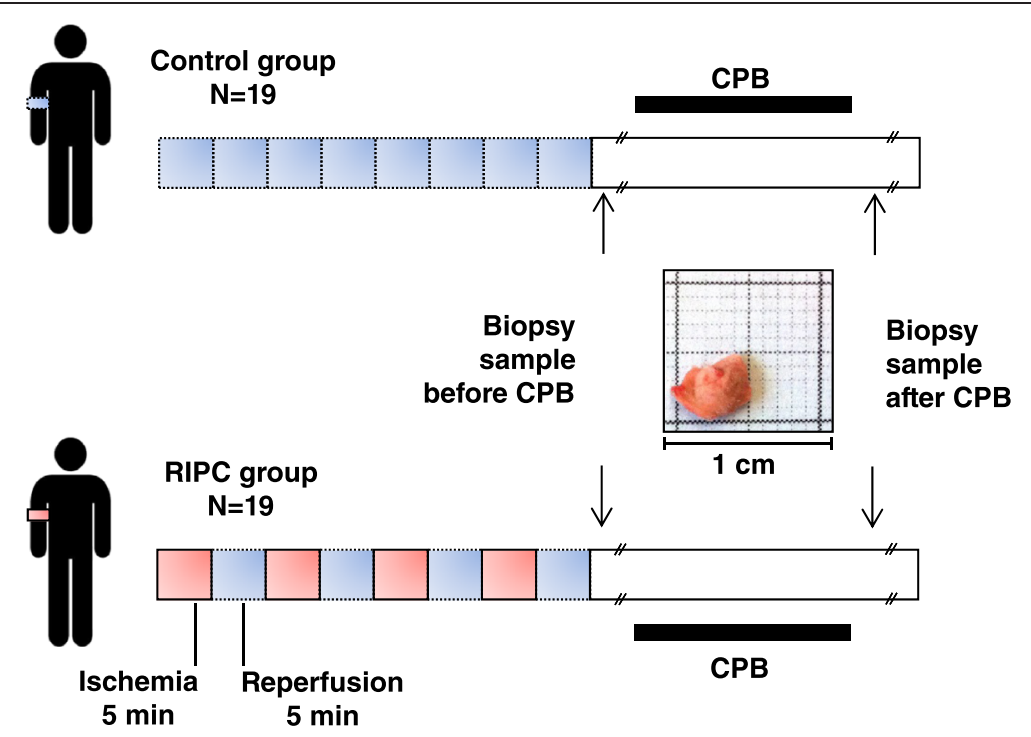

Figure 1 Experimental setting. RIPC was performed by 4 cycles of 5 minutes of upper arm ischemia induced with a blood pressure cuff which was inflated to $200 \mathrm{mmHg}$. Each cycle of ischemia was followed by 5 minutes of reperfusion. In the control group 4 cycles of 5-minutes blood-pressure cuff inflation to $20 \mathrm{mmHg}$ and 5-minutes cuff deflation were applied. Cardiac biopsies were obtained before and after CPB. CPB, cardiopulmonary bypass; RIPC, remote ischemic preconditioning.

Westernblotting was performed with samples of each patient separately. Protein extraction from cardiac tissue biopsies was performed with RIPA buffer containing $150 \mathrm{mM}$ sodium chloride, $1.0 \% \mathrm{NP}-40,0.1 \%$ sodium dodecyl sulfate (SDS), $1 \%$ sodium deoxycholate, $50 \mathrm{mM}$ Tris- $\mathrm{HCl}$ ( $\mathrm{pH}$ 7.6; all from Sigma-Aldrich, Hamburg, Germany). Protein concentrations were determined with a BCA Protein Assay Kit (Pierce Biotechnology, Rockford, USA). Samples were boiled for 5 minutes after addition of SDS polyacrylamide gel electrophoresis (PAGE) sample buffer $(62.5 \mathrm{mM}$ Tris- $\mathrm{HCl}, 2 \%$ SDS, 10\% glycerol, $5 \% \beta$-mercaptoethanol, all from Sigma-Aldrich). An equal amount of protein $(50 \mu \mathrm{g})$ of each sample was separated by $10 \%$ SDS-PAGE and transferred onto a PVDF membrane (Amersham Pharmacia Biotech, Piscataway, USA). Membranes were then incubated in blocking solution (Starting Block T20; Fisher Scientific, Schwerte, Germany) for 1 hour at room temperature, followed by an overnight incubation with specific antibodies against thioredoxin-1 (Cell Signalling Technology, Danvers, USA; 1:1.000) or $\beta$ actin (Santa Cruz, Heidelberg, Germany; 1:1.000), which served as a loading control. After washing in TBS containing $0.05 \%$ Tween 20 (Sigma-Aldrich), the membranes were incubated for 1 hour with horseradish peroxidase conjugated pig anti-rabbit immunoglobulin G (Dako, Glostrup, Denmark; 1:10.000) referring to the manufacturer's instructions. The final reaction was visualized using enhanced chemiluminescence (ECL-Detection Reagents, GE Healthcare, Munich, Germany), and the membrane was exposed to $x$-ray film. Images were taken and the intensities of the respective bands were densitometrically analysed with the software Image (v1.41o, NIH). Protein expression levels of thioredoxin were relativized to the intensity of the respective actin band and depicted as arbitrary units (a.u.).

\section{Enzyme Linked Immunosorbent Assay (ELISA)}

Human thioredoxin ELISAs (Biozol, Eching, Germany; \#USC-SEA702HU) were performed using unpooled samples from each patient separately. Briefly, protein extraction from cardiac tissue biopsies was performed with RIPA buffer as described above. $50 \mu \mathrm{g}$ of total protein from each patient were transferred into each well of a 96-well plate and all further steps were performed according to the manufacturer's protocol. The amount of thioredoxin was relativized to the total protein within the respective sample. As suggested in the manufacturer's protocol, hemolytic tissue lysates (HTLs) were excluded from further analyses (control before $\mathrm{CPB}, 9$ HTLs; control after CPB, 3 HTLs; RIPC before CPB, 0 HTLs; control after CPB, 0 HTLs).

\section{Statistical analysis}

Statistics were performed using the software GraphPad Prism version 5.01 for Windows. Each data set was tested for normality using the D'Agostino and Pearson omnibus test. Two way ANOVA in combination with Bonferroni post-tests were employed for analyses of the Westernblotting results, while due to missing data points (excluded HTLs) in the control group, ELISA data were evaluated using unpaired T-tests. Variables are expressed as mean \pm SEM. 


\section{Results}

Profiling of cell stress protein expression in cardiac tissue Proteome profiling employing cardiac tissue of cardiosurgical control patients and cardiosurgical patients undergoing RIPC revealed an increased expression of $26.9 \%(7 / 26)$ of stress associated proteins in RIPC tissue obtained before CPB [proteins up-regulated in the RIPC group: Carbonic anhydrase IX (CA IX), cytochrome C (Cyt C), heat shock protein-60 (HSP-60), heat shock protein-70 (HSP-70), phospho JNK (pJNK), superoxide dismutase 2 (SOD2), thioredoxin-1 (Thio-1)], while expression levels of $3.8 \%(1 / 26)$ of the proteins were down-regulated compared to the control group [proteins down-regulated in the RIPC group: Sirtuin 2 (SIRT2)]. In cardiac tissue obtained after CPB, only one of the proteins $3.8 \%(1 / 26)$ was slightly up-regulated in the RIPC group [proteins upregulated in the RIPC group: Phospho-p38 alpha (pp38 $\alpha$ )] while compared to the control group, expression levels of $26.9 \%(7 / 26)$ of the proteins were down-regulated [proteins down-regulated: Cytochrome $\mathrm{C}$ (Cyt C), heat shock protein-60 (HSP-60), heat shock protein-70 (HSP70), phospho heat shock protein-27 (pHSP-27), phospho JNK (pJNK), sirtuin 2 (SIRT2), thioredoxin-1 (Thio-1); Figure 2]. A detailed analysis of the protein expression in control and RIPC cardiac tissue samples obtained before and after $\mathrm{CPB}$ is shown in Figure 3.

\section{Semi-quantitative evaluation of thioredoxin protein expression in cardiac tissue}

One of the proteins that showed a strong expression within the cardiac tissue and that was also regulated by RIPC is thioredoxin, a small redox protein and at least in animal studies, a possible candidate for cardioprotection $[32,33,37,38]$. Based on our results of the human proteome profiling approach which was performed with pooled tissue samples of the respective patients, we decided to further focus on thioredoxin as a potential molecule conferring RIPC-mediated cardioprotection and investigated the expression of thioredoxin in each patient separately. Westernblotting results mainly confirmed the outcome of the protein arrays, showing an increased expression of thioredoxin in cardiac tissue of RIPC patients

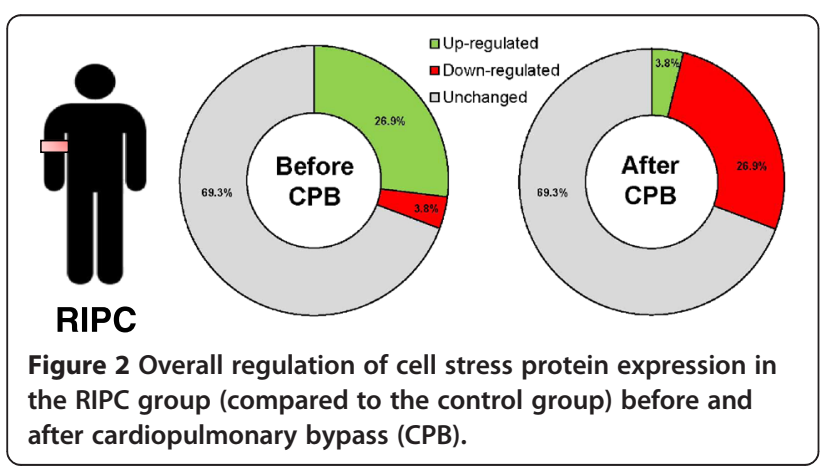

that was obtained before CPB (RIPC: $5.36 \pm 0.85$ a.u.; control: $3.23 \pm 0.39$ a.u.; $\mathrm{P}<0.05$, Figure 4), while no statistically significant differences in thioredoxin protein expression levels were detected in samples taken after CPB (RIPC, $3.94 \pm 0.73$ a.u.; control, $2.79 \pm 0.31$ a.u.; $\mathrm{P}>0.05$; Figure 4).

\section{Quantification of thioredoxin protein expression in cardiac tissue}

Based on the results of the semi-quantitative Westernblotting experiments, we furthermore performed thioredoxin specific ELISAs to quantify the amount of the protein within the respective cardiac tissue samples of each patient and correlate it to the total amount of protein within the sample. A statistically significant increase of thioredoxin protein expression was again only detected in samples of RIPC patients that were obtained before CPB (RIPC: $0.30 \pm 0.02 \mathrm{ng} / \mathrm{mg}$ protein; control: $0.24 \pm$ $0.02 \mathrm{ng} / \mathrm{mg}$ protein; $\mathrm{P}<0.05$; Figure 5), while a tendency towards increased thioredoxin expression was found in the RIPC tissue samples taken after CPB (RIPC: $0.32 \pm$ $0.03 \mathrm{ng} / \mathrm{mg}$ protein; control: $0.25 \pm 0.02 \mathrm{ng} / \mathrm{mg}$ protein; $\mathrm{P}=0.05$; Figure 5).

\section{Discussion}

Several clinical trials have suggested RIPC as an efficient and straightforward intervention to protect the heart from ischemia reperfusion injury which is a common perioperative complication during various surgical procedures [8,9,13,16,39-41]. Despite these encouraging clinical data on RIPC-mediated cardioprotection, the underlying mechanisms -especially within the myocardial tissue- are still discussed controversially $[17,20]$. Detailed knowledge about the molecular and cellular events that are associated with RIPC-mediated cardioprotection could however help to increase the effectiveness of RIPC and further improve patient outcome. Therefore, in the last years we have conducted several studies and investigated the effects of RIPC on ischemia/reperfusion injury in the heart focussing on the potential mechanisms that transfer the RIPC signal within the myocardium $[26,27,42,43]$.

In the study presented, we performed proteomic profiling using cardiac tissue from cardiosurgical patients with cardiopulmonary bypass $(\mathrm{CPB})$ that were subjected to RIPC or sham intervention.

Several stress associated proteins were found to be strongly expressed in tissue obtained after CPB. In myocardial samples of the control group, heat shock proteins (HSP) and especially the phosphorylated form of HSP-27 are up-regulated after $\mathrm{CPB}$. These findings are not surprising as surgery as well as the implementation of the $\mathrm{CPB}$ are stress factors and other groups have also shown that cardiac surgery results in an increased expression of heat shock proteins within the respective tissue $[44,45]$. 


\section{Before CPB \\ Control RIPC}

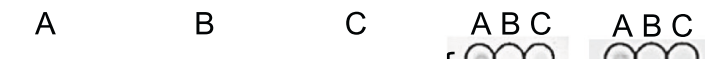

pp38a HIF2a ADAMTS1_\$8 808

pp53 pHSP-27 Bcl-2 $\left\{\begin{array}{l}1800 \\ 8080\end{array}\right.$

PON1 HSP-60 CAIX $\quad \begin{array}{llll}1808 & 8988\end{array}$

PON2 HSP-70 Cited2 $\{800$

PON3 IDO coX-2 $\{808$

Thio-1 pJNK Cytc $\{80$

SIRT2 NFkB1 Dkk-4 $\{\$ 28$

SOD2 p21/CIP1 FABP-1 - 800

$-\mathrm{Ct}$

p27

HIF1
After CPB

Control RIPC

A B C ABC

$-808$

$\infty 00$

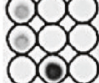

800

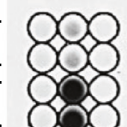

888

$-808$
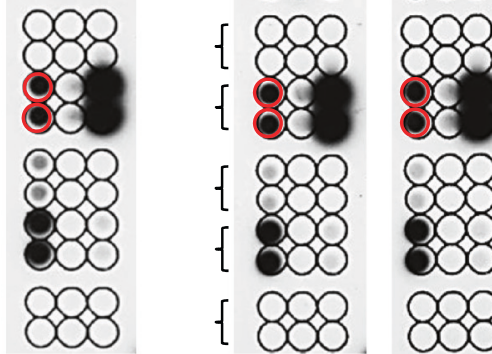

- 80

- 8838

- 828

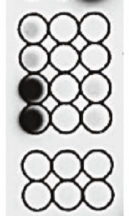

\begin{tabular}{|c|c|c|c|c|}
\hline \multirow[b]{2}{*}{ Protein } & \multicolumn{2}{|c|}{ Before CPB } & \multicolumn{2}{|c|}{ After CPB } \\
\hline & Control (a.u.) & RIPC (a.u.) & Control (a.u.) & RIPC (a.u.) \\
\hline \multirow[t]{2}{*}{ CA IX } & 12.8 & 19.0 & 2.0 & 2.0 \\
\hline & 12.9 & 18.2 & 2.4 & 1.7 \\
\hline \multirow[t]{2}{*}{ Cyt C } & 148.7 & 188.0 & 226.0 & 191.7 \\
\hline & 168.3 & 201.6 & 222.4 & 202.9 \\
\hline \multirow[t]{2}{*}{ HSP-60 } & 8.6 & 13.9 & 15.0 & 7.6 \\
\hline & 9.1 & 15.7 & 18.1 & 11.3 \\
\hline \multirow[t]{2}{*}{ HSP-70 } & 57.8 & 77.2 & 83.6 & 68.3 \\
\hline & 58.5 & 77.3 & 84.8 & 66.5 \\
\hline \multirow[t]{2}{*}{ pHSP-27 } & 1.4 & 2.8 & 44.3 & 39.9 \\
\hline & 0.3 & 2.7 & 45.5 & 40.5 \\
\hline \multirow[t]{2}{*}{ pp38a } & 12.5 & 12.4 & 14.0 & 14.7 \\
\hline & 14.5 & 15.2 & 13.6 & 15.2 \\
\hline \multirow[t]{2}{*}{ pJNK } & 7.9 & 17.6 & 22.3 & 17.6 \\
\hline & 7.0 & 18.7 & 20.4 & 17.5 \\
\hline \multirow[t]{2}{*}{ SIRT2 } & 29.7 & 21.3 & 14.9 & 10.7 \\
\hline & 31.3 & 23.4 & 16.7 & 13.5 \\
\hline \multirow[t]{2}{*}{ SOD2 } & 72.2 & 82.5 & 93.2 & 92.5 \\
\hline & 72.6 & 81.9 & 93.6 & 90.5 \\
\hline \multirow[t]{2}{*}{ Thio-1 } & 55.1 & 63.4 & 68.7 & 59.2 \\
\hline & 53.4 & 63.5 & 67.9 & 57.4 \\
\hline
\end{tabular}

Figure 3 (See legend on next page.) 
(See figure on previous page.)

Figure 3 Proteome profiling of cell stress proteins. Equal amounts of protein from control $(\mathrm{N}=18)$ and RIPC patients ( $\mathrm{N}=18)$ were pooled and employed in the array. Only proteins with signal intensities $\geq 10 \%$ of the internal reference control protein spot (not shown) were quantified. Numbers in the table represent the densitometric intensities of duplicate sample spots. pp38a, phospho-p38 alpha (T181/Y185); HIF2a, hypoxia inducible factor 2 alpha; ADAMTS1, a disintegrin and metalloproteinase with thrombospondin motifs 1; pp53, phospho-p53 (S46); pHSP-27, phospho heat shock protein-27; BCl-2, B cell lymphoma-2; PON1, paraoxonase 1; HSP-60, heat shock protein-60; CA IX, carbonic anhydrase IX; PON2, paraoxonase 2; HSP-70, heat shock protein-70; Cited2, Cbp/p300-interacting transactivator; PON3, paraoxonase 3; IDO, indoleamine 2,3-dioxygenase; COX-2, cyclooxygenase-2; Thio-1, thioredoxin-1; pJNK, phospho c-Jun n-terminal kinase (T183/Y185); CytC, cytochrome C; SIRT2, sirtuin 2; NFkB1, nuclear factor kappa B1; Dkk-4, dickkopf-4; SOD2, superoxide dismutase 2; p21/CIP1, cyclin-dependent kinase inhibitor 1A; FABP-1, fatty acid binding protein-1; - Ctr, negative control; p27, cyclin-dependent kinase inhibitor 1B; HIF1a, hypoxia inducible factor 1 alpha; a.u., arbitrary units.

However, protein profiling also revealed that in tissue obtained before $\mathrm{CPB}$, several of the cell stress associated protein [e.g. HSP-70, cytochrome C (CytC), superoxide dismutase 2 (SOD2), thioredoxin-1 (Thio-1)] are upregulated in the RIPC group. This finding is of major interest as an increased expression of cell stress proteins may have a positive effect on the heart [46] and can induce cardioprotective mechanisms [47-49]. Animal studies suggested that besides the heat shock proteins, redox proteins like thioredoxin may also play a role in cardioprotection $[32,33,50,51]$. Thioredoxin is a small oxidoreductase enzyme which is ubiquitously found in many organisms from plants and bacteria to mammals. It represents a potent redox protein acting as antioxidant by
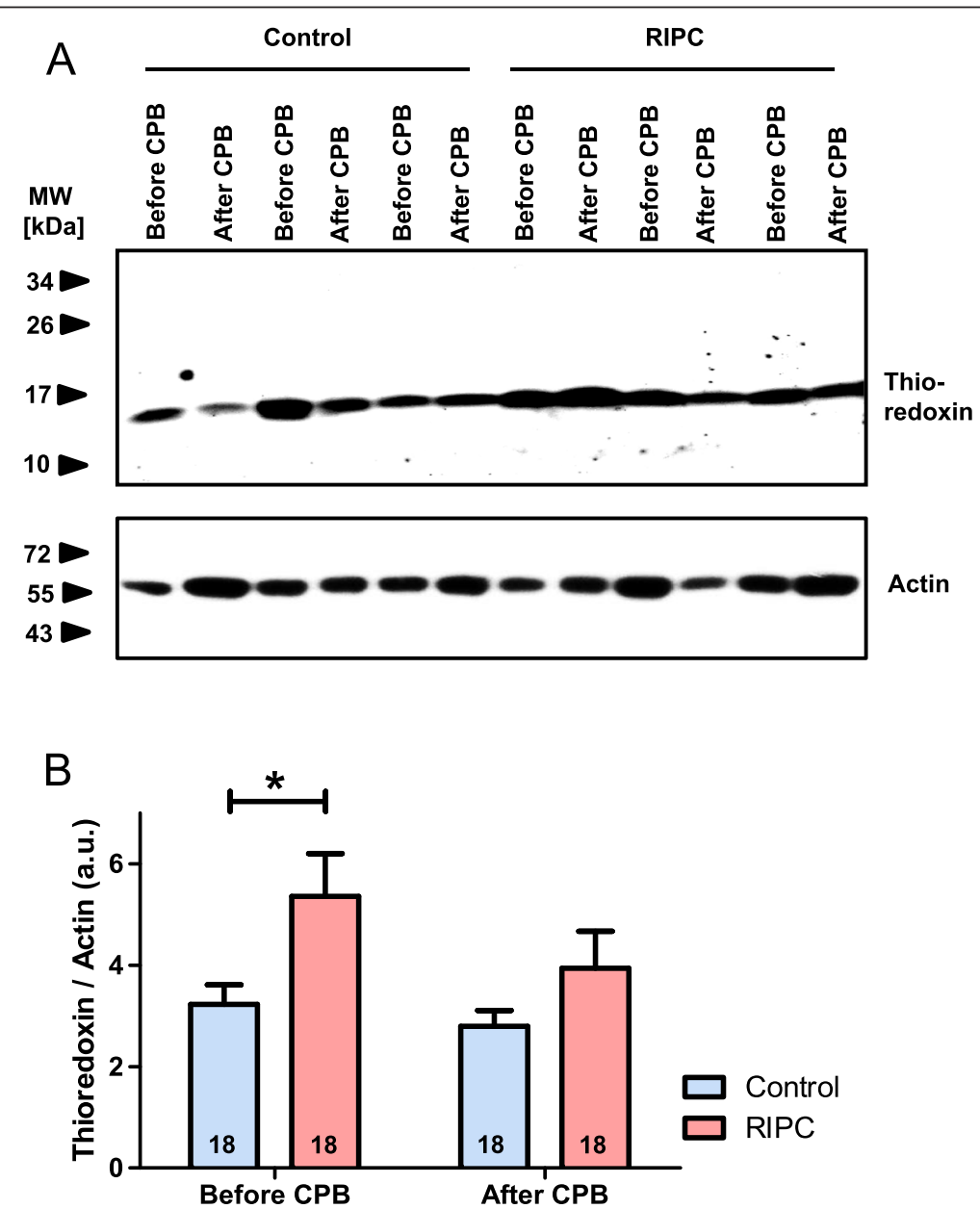

Figure 4 Semi-quantitative evaluation of thioredoxin protein expression. A: Representative Westernblotting experiment performed with cardiac tissue samples of 3 control and 3 RIPC patients. B: Evaluation of the relative protein expression levels of thioredoxin in control and RIPC patients. Numbers in the columns display the numbers of patients employed in the respective experiment. MW, molecular weight; kDa, kiloDalton; a.u., arbitrary units; columns display the mean; bars denote SEM; *, P < 0.05, two way ANOVA with Bonferroni post-test. 


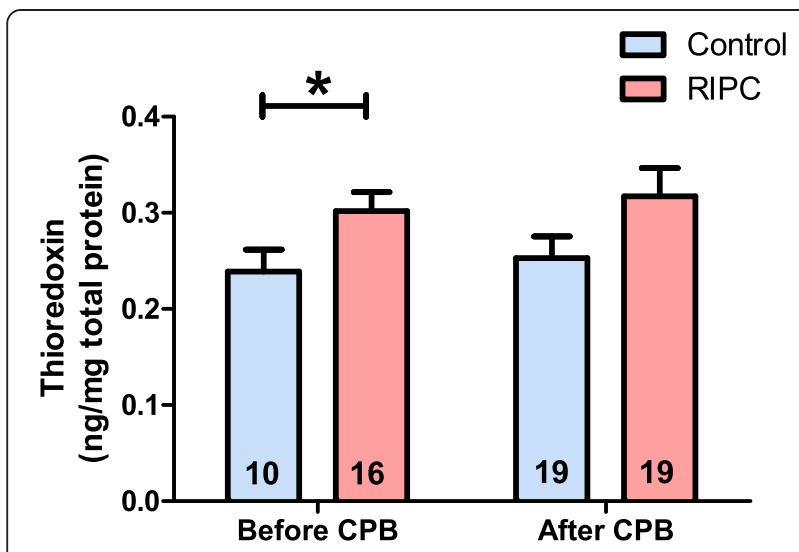

Figure 5 Quantification of thioredoxin protein expression by ELISA. The amount of thioredoxin protein is increased in tissue from RIPC patients that was obtained before CPB. Numbers in the columns display the numbers of patients employed in the respective experiment. Columns display the mean; bars denote SEM; *, $\mathrm{P}<0.05$, unpaired T-test.

facilitating the reduction of other proteins by cysteine thiol-disulfide exchange thereby abolishing oxidative stress within cells and tissues [28,29]. Concerning the protein expression of thioredoxin within the cardiac tissue, our cell stress proteome profiler arrays, Westernblotting experiments and thioredoxin ELISAs all revealed that RIPC leads to a statistically significant increased expression of the protein in cardiac tissue obtained before, but not after CPB. These findings are in accordance with our recently published studies, which also suggested that RIPC-mediated effects are mainly evident in tissue derived before but not in tissue obtained after CPB [26,27]. The reasons for this observation might be based on the fact that the immunological response to the extracorporeal circulation during CPB generates a systemic inflammatory response syndrome (SIRS) that is associated with the release of various cytokines [52,53] which may mask possible RIPC-mediated effects in tissue obtained after CPB. On the other hand, it is known that ischemic preconditioning represents a biphasic phenomenon with a first and a second window of protection [54]. The early phase of protection develops quickly within minutes from the initial ischemic conditioning event and lasts for 2 to 3 hours. This is followed by a delayed phase that begins after 12 to 24 hours and lasts up to 4 days. In our study, samples taken before CPB fall into the first window of protection, while tissue that is derived after $\mathrm{CPB}$ possibly falls into the gap between the two windows, which explains why only few proteins are found to be up-regulated by RIPC in tissue samples derived after $\mathrm{CPB}$.

Our findings that several cell stress associated proteins, including thioredoxin, exhibit a temporary upregulation by RIPC may be of value for future studies employing RIPC to reduce morbidity and mortality in cardiosurgical patients. In a clinical perspective, cardiosurgical patients seem to profit from an early and temporary induction of cell stress associated proteins by transient episodes of remote ischemia before surgery. However, the RIPCinduced response in the remote target organ (e.g. heart) most likely relies on a delicate balance between protective and potentially harmful RIPC mediators - circulating factors as well as local target tissue derived molecules. The expression of these mediators needs to be precisely adjusted to exploit the cardioprotective potential of RIPC and to avoid possible adverse effects of RIPC. Therefore, optimizing the currently available RIPC protocols $[8,55]$ by adjusting the RIPC location, timing, duration and cycle numbers as well as taking into consideration possible comorbidities of RIPC patients [56] may enhance the potential of RIPC-mediated cardioprotection, resulting in an improved patient outcome and may help to reduce morbidity as well as mortality after cardiosurgical interventions.

There are some limitations of the study which need to be considered: (i) Post-operative or clinical endpoints were not evaluated in the experimental study presented. However, clinical outcome parameters are described in the context of our previous pilot study (Additional file 1: Table S1; [42,43]). (ii) Depending on the patient and surgical procedure the first biopsy (before $\mathrm{CPB}$ ) was collected between 15 minutes and 100 minutes after RIPC. As the second biopsy sample was collected immediately after CPB the time period between the collection of the first and second sample varied between the patients. (iii) Based on surgical and ethical limitations only cardiac tissue of the right atrium and no ventricular tissue could be obtained and we cannot exclude the possibility that tissue taken after $\mathrm{CPB}$ was affected by e.g. shear stress induced by the suture of the venous cannula (iv) Due to methodological constraints and the limited amount of cardiac tissue available, not all experiments could be performed with samples of all patients. However, it was assured that in all experiments patients in the RIPC group had reduced myocardial damage, which was demonstrated by significantly lower serum cTnT levels in the RIPC group.

\section{Conclusions}

In the present study we performed proteomic profiling with heart tissue obtained from cardiosurgical patients that were subjected to RIPC or sham intervention. We provide evidence for thioredoxin as a RIPC-induced factor in the heart of cardiosurgical patients and identified several cell stress associated proteins that are regulated by RIPC and may play a role in RIPC-mediated cardioprotection. 


\section{Additional file}

Additional file 1: Table S1. Clinical and experimental trials with relation to the actual study.

\section{Competing interests}

The authors declare that they have no competing interests.

\section{Authors' contributions}

PM, MG and JC were involved in the acquisition and evaluation of the clinical data. KZ, MG and PM performed the analyses of the tissue samples. KZ, PM and MA were responsible for the study concept and design, as well as drafting of the manuscript. JS, MS and KDZ were involved in the statistical analyses and critical revision of the manuscript for important intellectual content. All authors read and approved the final manuscript.

\section{Acknowledgements}

We thank C. Schildhauer, and K. Masuhr for technical assistance. This study was funded by research grants from the German Society of Anaesthesiology (PM) and by the International Anesthesia Research Society (PM).

\section{Author details}

'Department of Anaesthesiology and Intensive Care Medicine, University Hospital Schleswig-Holstein, Schwanenweg 21, 24105 Kiel, Germany. ${ }^{2}$ Department of Anaesthesiology, Intensive Care Medicine and Pain Therapy, University Hospital Frankfurt, Frankfurt am Main, Germany. ${ }^{3}$ Department of Cardiovascular Surgery, University Hospital Schleswig-Holstein, Kiel, Germany.

\section{Received: 4 November 2014 Accepted: 16 January 2015}

\section{Published online: 27 January 2015}

\section{References}

1. Gottesman RF, McKhann GM, Hogue CW. Neurological complications of cardiac surgery. Semin Neurol. 2008;28:703-15.

2. Newman MF, Wolman R, Kanchuger M, Marschall K, Mora-Mangano C, Roach $\mathrm{G}$, et al. Multicenter preoperative stroke risk index for patients undergoing coronary artery bypass graft surgery. Multicenter Study of Perioperative Ischemia (McSPI) Research Group. Circulation. 1996;94:II74-80.

3. Anselmi A, Abbate A, Girola F, Nasso G, Biondi-Zoccai GG, Possati G, et al. Myocardial ischemia, stunning, inflammation, and apoptosis during cardiac surgery: a review of evidence. Eur J Cardiothorac Surg. 2004;25:304-11.

4. Murry CE, Jennings RB, Reimer KA. Preconditioning with ischemia: a delay of lethal cell injury in ischemic myocardium. Circulation. 1986;74:1124-36.

5. Gross ER, Gross GJ. Ischemic preconditioning and myocardial infarction: an update and perspective. Drug Discov Today Dis Mech. 2007;4:165-74.

6. Hausenloy DJ, Boston-Griffiths E, Yellon DM. Cardioprotection during cardiac surgery. Cardiovasc Res. 2012;94:253-65.

7. Heusch G, Boengler K, Schulz R. Cardioprotection: nitric oxide, protein kinases, and mitochondria. Circulation. 2008;118:1915-9.

8. Przyklenk K. Reduction of myocardial infarct size with ischemic "conditioning": physiologic and technical considerations. Anesth Analg 2013;117:891-901.

9. Przyklenk K, Whittaker P. Remote ischemic preconditioning: current knowledge, unresolved questions, and future priorities. J Cardiovasc Pharmacol Ther. 2011;16:255-9.

10. Ali ZA, Callaghan CJ, Lim E, Ali AA, Nouraei SA, Akthar AM, et al. Remote ischemic preconditioning reduces myocardial and renal injury after elective abdominal aortic aneurysm repair: a randomized controlled trial. Circulation. 2007;116:198-1105.

11. Cheung MM, Kharbanda RK, Konstantinov IE, Shimizu M, Frndova H, Li J, et al. Randomized controlled trial of the effects of remote ischemic preconditioning on children undergoing cardiac surgery: first clinical application in humans. J Am Coll Cardiol. 2006;47:2277-82.

12. Gunaydin B, Cakici I, Soncul H, Kalaycioglu S, Cevik C, Sancak B, et al. Does remote organ ischaemia trigger cardiac preconditioning during coronary artery surgery? Pharmacol Res. 2000;41:493-6.

13. Hausenloy DJ, Mwamure PK, Venugopal V, Harris J, Barnard M, Grundy E, et al. Effect of remote ischaemic preconditioning on myocardial injury in patients undergoing coronary artery bypass graft surgery: a randomised controlled trial. Lancet. 2007;370:575-9.
14. Hoole SP, Heck PM, Sharples L, Khan SN, Duehmke R, Densem CG, et al. Cardiac Remote Ischemic Preconditioning in coronary stenting (CRISP Stent) study: a prospective, randomized control trial. Circulation. 2009;119:820-7.

15. Kharbanda RK, Li J, Konstantinov IE, Cheung MM, White PA, Frndova H, et al. Remote ischaemic preconditioning protects against cardiopulmonary bypass-induced tissue injury: a preclinical study. Heart. 2006;92:1506-11.

16. Thielmann M, Kottenberg E, Kleinbongard P, Wendt D, Gedik N, Pasa S, et al Cardioprotective and prognostic effects of remote ischaemic preconditioning in patients undergoing coronary artery bypass surgery: a single-centre randomised, double-blind, controlled trial. Lancet. 2013;382:597-604

17. Hausenloy DJ, Yellon DM. Preconditioning and postconditioning: underlying mechanisms and clinical application. Atherosclerosis. 2009;204:334-41.

18. Heidbreder M, Naumann A, Tempel K, Dominiak P, Dendorfer A. Remote vs. ischaemic preconditioning: the differential role of mitogen-activated protein kinase pathways. Cardiovasc Res. 2008;78:108-15.

19. Wolfrum S, Schneider K, Heidbreder M, Nienstedt J, Dominiak P, Dendorfer A. Remote preconditioning protects the heart by activating myocardial PKCepsilon-isoform. Cardiovasc Res. 2002;55:583-9.

20. Sadat U. Signaling pathways of cardioprotective ischemic preconditioning Int J Surg. 2009;7:490-8.

21. Hausenloy DJ, Iliodromitis EK, Andreadou I, Papalois A, Gritsopoulos G, Anastasiou-Nana M, et al. Investigating the signal transduction pathways underlying remote ischemic conditioning in the porcine heart. Cardiovasc Drugs Ther. 2012;26:87-93.

22. Sicard P, Clark JE, Jacquet S, Mohammadi S, Arthur JS, O'Keefe SJ, et al. The activation of p38 alpha, and not p38 beta, mitogen-activated protein kinase is required for ischemic preconditioning. J Mol Cell Cardiol. 2010:48:1324-8.

23. Heusch G, Musiolik J, Kottenberg E, Peters J, Jakob H, Thielmann M. STAT5 activation and cardioprotection by remote ischemic preconditioning in humans: short communication. Circ Res. 2012;110:111-5.

24. Michelsen MM, Stottrup NB, Schmidt MR, Lofgren B, Jensen RV, Tropak M, et al. Exercise-induced cardioprotection is mediated by a bloodborne, transferable factor. Basic Res Cardiol. 2012;107:1-9.

25. Shimizu M, Tropak M, Diaz RJ, Suto F, Surendra H, Kuzmin E, et al. Transient limb ischaemia remotely preconditions through a humoral mechanism acting directly on the myocardium: evidence suggesting cross-species protection. Clin Sci (Lond). 2009;117:191-200.

26. Zitta K, Meybohm P, Bein B, Gruenewald M, Lauer F, Steinfath M, et al. Activities of cardiac tissue matrix metalloproteinases 2 and 9 are reduced by remote ischemic preconditioning in cardiosurgical patients with cardiopulmonary bypass. J Transl Med. 2014;12:94.

27. Albrecht M, Zitta K, Bein B, Wennemuth G, Broch O, Renner J, et al. Remote ischemic preconditioning regulates HIF-1 alpha levels, apoptosis and inflammation in heart tissue of cardiosurgical patients: a pilot experimental study. Basic Res Cardiol. 2013;108:314-27.

28. Lee S, Kim SM, Lee RT. Thioredoxin and thioredoxin target proteins: from molecular mechanisms to functional significance. Antioxid Redox Signal. 2013;18:1165-207.

29. Collet JF, Messens J. Structure, function, and mechanism of thioredoxin proteins. Antioxid Redox Signal. 2010;13:1205-16.

30. Haendeler J, Tischler V, Hoffmann J, Zeiher AM, Dimmeler S. Low doses of reactive oxygen species protect endothelial cells from apoptosis by increasing thioredoxin-1 expression. FEBS Lett. 2004;577:427-33.

31. Haendeler J, Hoffmann J, Tischler V, Berk BC, Zeiher AM, Dimmeler S. Redox regulatory and anti-apoptotic functions of thioredoxin depend on S-nitrosylation at cysteine 69. Nat Cell Biol. 2002;4:743-9.

32. Chiueh CC, Andoh T, Chock PB. Induction of thioredoxin and mitochondrial survival proteins mediates preconditioning-induced cardioprotection and neuroprotection. Ann N Y Acad Sci. 2005;1042:403-18.

33. Nicholson CK, Lambert JP, Molkentin JD, Sadoshima J, Calvert JW. Thioredoxin 1 is essential for sodium sulfide-mediated cardioprotection in the setting of heart failure. Arterioscler Thromb Vasc Biol. 2013;33:744-51.

34. Yoshioka J, Lee RT. Thioredoxin-interacting protein and myocardial mitochondrial function in ischemia-reperfusion injury. Trends Cardiovasc Med. 2014;24:75-80.

35. Licka M, Zimmermann R, Zehelein J, Dengler TJ, Katus HA, Kubler W. Troponin $T$ concentrations 72 hours after myocardial infarction as a serological estimate of infarct size. Heart. 2002;87:520-4. 
36. Mair P, Mair J, Seibt I, Wieser C, Furtwaengler W, Waldenberger F, et al. Cardiac troponin T: a new marker of myocardial tissue damage in bypass surgery. J Cardiothorac Vasc Anesth. 1993;7:674-8.

37. Das DK. Thioredoxin regulation of ischemic preconditioning. Antioxid Redox Signal. 2004;6:405-12.

38. Turoczi T, Chang VW, Engelman RM, Maulik N, Ho YS, Das DK. Thioredoxin redox signaling in the ischemic heart: an insight with transgenic mice overexpressing Trx1. J Mol Cell Cardiol. 2003;35:695-704.

39. Heusch G. Cardioprotection: chances and challenges of its translation to the clinic. Lancet. 2013;381:166-75.

40. Lim SY, Hausenloy DJ. Remote ischemic conditioning: from bench to bedside. Front Physiol. 2012;3:27.

41. Hausenloy DJ, Yellon DM. The therapeutic potential of ischemic conditioning: an update. Nat Rev Cardiol. 2011;8:619-29.

42. Meybohm P, Zacharowski K, Cremer J, Roesner J, Kletzin F, Schaelte G, et al. Remote ischaemic preconditioning for heart surgery. the study design for a multi-center randomized double-blinded controlled clinical trial-the RIPHeart-Study. Eur Heart J. 2012;33:1423-6.

43. Meybohm P, Renner J, Broch O, Caliebe D, Albrecht M, Cremer J, et al. Postoperative neurocognitive dysfunction in patients undergoing cardiac surgery after remote ischemic preconditioning: a double-blind randomized controlled pilot study. PLoS One. 2013;8:e64743-3.

44. Chaudhry AZ, Diodato MD, Massad MG. Heat shock protein expression during cardiac surgery. World J Surg. 2010;34:682-3.

45. Yellon DM, Latchman DS, Marber MS. Stress proteins-an endogenous route to myocardial protection: fact or fiction? Cardiovasc Res. 1993;27:158-61.

46. Stress proteins and myocardial protection. Lancet. 1991;337:271-2.

47. Morris SD, Yellon DM, Marber MS. Stress proteins: a future role in cardioprotection? Heart. 1996;76:97-8.

48. Wei H, Campbell W, Vander Heide RS. Heat shock-induced cardioprotection activates cytoskeletal-based cell survival pathways. Am J Physiol Heart Circ Physiol. 2006;291:H638-47.

49. Peng W, Zhang $Y$, Zheng $M$, Cheng $H$, Zhu W, Cao CM, et al. Cardioprotection by CaMKII-deltaB is mediated by phosphorylation of heat shock factor 1 and subsequent expression of inducible heat shock protein 70. Circ Res. 2010;106:102-10.

50. Tullio F, Angotti C, Perrelli MG, Penna C, Pagliaro P. Redox balance and cardioprotection. Basic Res Cardiol. 2013;108:392.

51. Penna C, Perrelli MG, Pagliaro P. Mitochondrial pathways, permeability transition pore, and redox signaling in cardioprotection: therapeutic implications. Antioxid Redox Signal. 2013;18:556-99.

52. Baehner T, Boehm O, Probst C, Poetzsch B, Hoeft A, Baumgarten G, et al. Cardiopulmonary bypass in cardiac surgery. Anaesthesist. 2012;61:846-56

53. Jaffer U, Wade RG, Gourlay T. Cytokines in the systemic inflammatory response syndrome: a review. HSR Proc Intensive Care Cardiovasc Anesth. 2010;2:161-75.

54. Huffmyer J, Raphael J. Physiology and pharmacology of myocardial preconditioning and postconditioning. Semin Cardiothorac Vasc Anesth. 2009;13:5-18.

55. Bousselmi R, Lebbi MA, Ferjani M. Myocardial ischemic conditioning: physiological aspects and clinical applications in cardiac surgery. J Saudi Heart Assoc. 2014;26:93-100.

56. McCafferty K, Forbes S, Thiemermann C, Yaqoob MM. The challenge of translating ischemic conditioning from animal models to humans: the role of comorbidities. Dis Model Mech. 2014;7:1321-33.

\section{Submit your next manuscript to BioMed Central and take full advantage of:}

- Convenient online submission

- Thorough peer review

- No space constraints or color figure charges

- Immediate publication on acceptance

- Inclusion in PubMed, CAS, Scopus and Google Scholar

- Research which is freely available for redistribution 